\title{
Kutadgu Bilig'de Tespit Edilen \\ Bazı Duygu Fiilleri
}

\author{
DOÇ. DR.SERPIL SOYDAN* - ASLI ÖZKAN ŞEN**
}

\section{Öz}

Mutluluk veren bilgi anlamına gelen, 6645 beyitten oluşan Kutadgu Bilig, mesnevi türüne örnek teşkil eden önemli bir eserdir. Bu eser, insana her iki dünyada kutlu olma yolunu göstermek amacryla yazılmıştır. Bu çalışmada, bir ahlâk ve öğüt kitabı olan Kutadgu Bilig'deki mental fiillerden duygu fiilleri incelenmeye çalışılmıştır. Mental fiiller, anlambilim temeline dayalı olarak incelenmektedir. Anlambilim, dilde kodlanmış anlamlarla ilgilenmektedir. Mental fiillerden durum ifade eden duygu fiilleri beş başlık altında değerlendirilmiştir. Toplamda yirmi sekiz fiil tespit edilmiştir. Tespit edilen bu fiillerin tarihî dönemlere ait sözlüklerde tanıklanıp tanıklanmadığı incelenmiştir. Bu fiillerin tasnifi ve sayısal verileri şöyledir: 1) Dilek ve istek ifade eden 14 fiil tespit edilmiştir. Kök hâlinde olan:1, Gövde hâlinde olan: 8, Birleşik fiiller: isim + yrd. eylemle oluş. bir: 4, kurallı birleşik fiil: 1,2) Mutluluk ve birliktelik ifade eden 8 fiil tespit edilmiştir. Bu fiiller şöyledir: Gövde hâlinde: 7, Birleşik fiiller: isim + yrd. eylemle oluş. bir. f. 1, 3) Coşku ve neşe ifade eden 4 fiil tespit edilmiştir. Bu fiillerin tasnifi ve sayısal verileri şöyledir: Kök hâlinde olan: 1, Gövde hâlinde olan: 3. 4) Sayg1 ve hürmet ifade eden gövde hâlinde bir (1) fiil, 5) Öfke ve nefret ifade eden kök hâlinde bir (1) fiil tespit edilmiştir.

Anahtar Kelimeler: Kutadgu Bilig, duygu fiilleri, dilek fiilleri, mutluluk fiilleri, birleşik fiiller

\section{SOME EMOTION VERBS DETECTED IN KUTADGU BİLİG}

\begin{abstract}
Kutadgu Bilig, which means knowledge that gives happiness, consists of 6645 couplets, is an important work that sets an example for the type of masnavi. This work was written to show man the way to be happy in both worlds. Mental verbs are examined based on semantics. Semantics deals with language-coded meanings. Emotional verbs, which express a situation from mental verbs, are evaluated under five headings. In total, twenty-eight verbs were identified. It was examined whether these verbs were witnessed in historical dictionaries. The classification and numerical data of these verbs are as follows: 1) Fourteen verbs expressing wishes and wishes have been identified. Verb in the form of base: one, Verbs in the form of a stem: eight, Combined verbs: noun + assist. combined verbs: four, regular compound verb: one 2) Eight verbs that express happiness and unity have been identified. These verbs are: Verbs in the form of a stem: seven, combined verbs: noun + assist. combined verbs: one. 3) Four verbs expressing enthusiasm and joy were identified. The classification and numerical data of these verbs are as follows: base form: one, Verbs in the form of a stem: three. 4)
\end{abstract}

\footnotetext{
* Niğde Ömer Halisdemir Üniversitesi, srp_syd78@hotmail.com, orcid: 0000-0001-7180-8769

** Niğde Ömer Halisdemir Üniversitesi, asliozkan01@hotmail.com, orcid: 0000-0001-8162-5472

Gönderilme Tarihi: 14 Ocak $2021 \quad$ Kabul Tarihi: 23 Mart 2021
} 
One verb (1) has been identified as a verb in the form of base which expresses respect and deference. 5) One verb (1) which expresses anger and hatred has been identified.

Keywords: Kutadgu Bilig, emotion verbs, wish verbs, happiness verbs, compound verbs.

\section{Gíriş}

İ

ngilizcede mental kavramı, ruhsal, zihinsel anlamlarındadır. İdrâk, algılama ve duyularla ilgili olan mental fiiller, anlam bilim temelinde incelenmiştir.

Lakoff ve Johnson'a göre (1980), ifade çeşitleri, vücutlarımız (algıyla ilgili motor aygıtlar, mental kapasiteler, duygusal tamamlama vb.), fiziksel çevremizle etkileşimimiz (dokunaklı, etkileyen objeler vb.) ve aynı kültürdeki diğer insanlarla etkileşimimizin (sosyal, politik, ekonomik, dinsel kurumlar yoluyla) ürünüdür. İfade alanları bu anlamda doğaldır. İfadenin bu doğal çeşitleri insan doğasının üretimleridir. Kültürden kültüre değişmekle birlikte bunlar evrensel sınıflardır (akt. Yaylagül, 2005, s.19).

Croft, Case Marking and the Semantics of Mental Verbs başlıklı çalışmasının 'The Phenomenon' alt başlığında mental verbs ve psych verbs terimleri eşdeğer sayarak, söz konusu fiilleri perception 'algi', cognition ' biliş' ve emotion 'duygu' (1993: 55) şeklinde üç gruba ayırırken; Garcia- Miguel et al 2005 'te ayn üç grup için feeling 'duygu', perception 'algı', cognition 'biliş' terimleri kullanılmaktadır. İkisi arasındaki tek fark 'duygu' teriminin farklı kelimelerle ifade edilmiş olmasıdır. Halliday 2014' te de mental süreçler üçe ayrılmıştır. Adlandırma Croft 1993’e göre çok daha farklıdır: görme (seeing), duygu (feeling) ve düşünme ( thinking) şeklindedir (akt. Yıldız, 2017, s.147).

Bayraktar (2017, s.461), duyu fiillerini, idrak etme sürecinin başlangıcı olan verilerin girdilerini belirten fiiller olarak ifade eder ve beş duyu organıla algılandı̆̆ını belirtir.

Yaylagül (2005, s.18), “Türk Runik Harfli Metinlerde Mental Fïller" adlı makalesinde mental fiiller hakkında şu açıklamalara yer verir: "Mental fiiller, anlambilim temelinde incelenmiştir. Anlambilimin seçkin bir tanımı İşaret Bilimi tarafından yapılmıştır. 1940'larda Danimarkalı dil bilimci Louis Trolle Hjelmslev tarafından kurulan İşaret Bilimin önemli isimlerinden biri olan Amerikalı filozof Charles Peirce (1931), bütün insan bilgisini işaret fikrine indirgemiş ve üç tip işaret teşhis etmiştir: İndeks (gönderimde bulunduğu nesne veya kavramlarla nedensel bir ilişki taşıyan bir işaret), ikon (gönderimde bulunduğu nesne veya kavramlarla benzerlik ilişkisi taşıyan bir işaret) ve sembol (gönderimde bulunduğu nesne veya kavramlarla yalnızca geleneksel bir ilişkisi olan bir işaret)".

Hirik ve Çolak'a göre (2017, s.263), “Mental fiiller, doğrudan düşüncenin kullanılarak gerçekleştirildiği, genellikle bir tetikleyici ile başlayan, psikolojik ve duygusal etkenlere doğrudan bağlı, çoğunlukla üçüncü kişiler tarafından gözlemlenemeyen, gözlemlendiği durumlarda da çeşitli anıuslamlama bağlantılarıyla bunu ortaya koyan fiiller" olarak tanımlanmaktadır. Mental süreç, psikolojik süreci başlatan hareketten bu hareketlerin sonucuna kadar geçen evre içerisindeki tüm olguları kapsamaktadır. Bu süreç içerisindeki olguların dildeki karşılığı ise mental fiillerdir.

Bunun dışında tarihî ve günümüz Türk lehçeleri üzerinde yapılan çalışmaların genellikle karşılaştırmalı mental fiil çalışmaları olduğu görülmektedir. ${ }^{1}$ Bu çalışmalardan biri olan, Mental Fiil Kavramı ve Türkmen Türkçesinde Mental Fiiller adlı doktora tezinde, Şahin (2012, s.45), mental fiillerin en önemli çıktısının idrak fiilleri olduğunu, duygu fiillerinin, biliş ve davranışı etkileyen ve uyumsal fonksiyonları olan temel bir faktör olarak da kabul edilip bir uyaranın yol açtığı genel bir uyarılma hâlinin, bilişsel süreçler tarafından değerlendirilmişs şekli olarak incelendiğini, dünyada 
bütün dillerde duyguları ifade eden fiillerin var olduğunu, mental sürecin zihinde meydana getirdiği hissî çıtıların duygu fiilleri olarak kabul edildiğini belirtir.

Ayrıca Şahin doktora tezinde, Türkmen Türkçesindeki mental fiilleri, Türkmence Türkçe sözlüğü tarayarak tespit etmiş, bu başlık altında, Eski ve Orta Türkçe Dönemi'nin en önemli eserlerinin sözlük kısmını da tarayıp bu eserlerde geçen mental fiil örneklerine yer vermiştir. Türkmen Türkçesindeki mental fiilleri, idrak, duygu ve algılama fiilleri olmak üzere üç grupta değerlendirir. Añlamak, akıl yetirmek, duymak, gızmak, keyplenmek, akıl bermek, nesihat bermek gibi fiilleri Türkiye ve Türkmen Türkçesinde küçük ses farklılıklarına rağmen mana ortaklığı taşıyan mental fiiller olarak değerlendirmiştir. Ayrıca çoğu yerde Türkmen ve Türkiye Türkçesindeki mental fiillerin Eski Türkçe döneminden beri anlam bakımından korunduğunu, kimi zaman anlam değişmesine ve gelişmesine uğradığını tespit etmiştir. Türkçede, Eski Türkçeden beri zihinle ilgili kavramları ifade eden bazı sözcüklerin, birden fazla anlamda kullanıldı̆̆ını, aynı kavramı karşılayan birden fazla sözcügün olduğunu belirtir ve şu örneğe yer verir: Türkiye Türkçesinde, düşünmek fiili, düşünmek manasının yanında "muhakeme etmek, aklından geçirmek" gibi manalara geldiğini, Türkmen Türkçesinde anlamak fiilini karşılayan anlamak, bilmek, duymak gibi kelimelerin olduğunu, Eski Türkçede zihin fiili olarak kabul edilen anlamak kavramının, "ö- sakınmak, tuyunmak vs." gibi birden fazla sözcükle ifade edilebildiği gibi, Türkiye Türkçesinde bu kavramın "kavramak, farkına varmak, hissetmek, bilmek, seçmek, görmek, akıl erdirmek...” gibi fiillerle karşılandığını belirtir.

Hüseyin Yıldız, Eski Uygurcada Göz Fiilleri adlı makalesinde, Eski Uygurcada tespit edilen göz fiillerinin bir kısmının temel anlamlı, bir kısmının yan anlam ya da metafor yoluyla oluşmuş fiillerden meydana geldiğini belirtir. Eski Uygurcada kullanılan görme fiillerinin temelde kör- köküne dayandığını, karagur- ve yum- fiillerinin yan anlam, arı, aşa-, soklun- fiillerinin ise mecaz anlam kazanarak "görmek" ya da "görmemek" anlamlarından birine gelecek kullanımlara sahip olduğunu belirtir.

Kıyal Kamchybekova Abdiraim, Kırgız Türkçesinde Kara- Duyu Fiili Anlamsal Özellikleri ve Kavram Alanı Üzerine adlı makalesinde, kara- fiili kapsamında 70 fiil tespit etmiş, bu fiilleri yapı açısından değerlendirmiş, 57 fiilde "bakmak" anlamını tespit etmiş, kara- duyu fiilinin temel oluşturmuş ve farklı anlamlar kazandırmış 13 birleşik fiilin kara- duyu fiilinin farklı anlamlarda kullanımı olarak ele alındığını belirtmiştir.

Ekrem Ayan, Yakup Türkdil, Kazak Türkçesinde Dokunma Duyu Fiilleri ve Anlam Zenginliği(2015) adlı makalesinde, Kazak Türkçesindeki 56 tane dokunma duyu fiili tespit etmiş ve bu duyu fiillerini temel-yan anlam, olumlu-olumsuz anlam, istemli-istemsiz ve fiziksel-zihinsel temas açısından incelemiştir.

Yaylagül (2010, s.101),duygu fiillerinin, mental fiillerin bir grubunu teşkil ettiğini ve ikinci aşamasını oluşturduğunu, etkiyi duyularla alma ve bunlara tepki göstermeyi anlattığını, duygusal tepkilerin bu fiiller dışında ünlemlerle, eksiltili cümle yapılarıyla vb. de aktarılabildiğini belirtir.

Melek Erdem, Oğuz Grubu Türk Lehçelerinde yer alan iletişim fiillerini “de-, söyle-, sor-, cevap ver-, bilgi ver-, haber ver-“" gibi konuşma eylemine dayalı fiilleri iletişim fiilleri olarak değerlendirmiştir. Bu fiilleri, lehçelerdeki kullanımına ve anlamına göre değerlendirmiş, ilaveten Seyit Nazar Ärnazarov'un, Türkmen Dilinde Sözleyiş İşlikleri (1982), adlı çalışmasında (akt. Erdem, 2007, s.97), farklı anlamlı söyleyiş fiillerinde fiilleri söyleme sürecinin içeriğini anlatan (duygu katkısı olmayan, olumlu duygu katkısı olan, olumsuz duygu katkısı olan), söyleme sürecinin tarzını anlatan (yüksek tonlu konuşmayı niteleyen, alçak sesli konuşmayı niteleyen, söyleme sürecinin hoşluğunu, 
güzelliğini anlatan, çok ve anlaşılmaz konuşmayı niteleyen fiiller olarak değerlendirmiş olduğunu ifade eder. Erkan Hirik, Türkiye Türkçesi Duyu Fiillerinde Anlam ve Kelime Sıklığı İlişkisi adlı makalesinde, duyu fiillerini çok anlamlılık ve kelime sıklığı açısından değerlendirmiştir. Duyu fiillerinden, öncelikle gör- fiilinin devamında sırasıyla işitme, tatma, dokunma ve koku alma duyularının olduğunu belirlemiştir.

Soydan ve Özkan, Kutadgu Bilig'de Bazı Duygu Fiilleri Üzerine Bir Değerlendirme adlı çalışmasında; Kutadgu Bilig'de tespit edilen yirmi dört fiili yapı bakımından şu başlıklar altında incelemiştir: 1.Iztırap ve acı ifade eden fiiller 2. Kaygı, endişe, telaş ifade eden fiiller 3.Korkma, ürkme, çekinme ifade eden fiillerdir.

Bu çalışmada, Abdiraim'in ve Yaylagül'ün çalışmasına benzer şekilde duygu ifade eden fiiller, yapı ve etimolojik açıdan incelenmiş, Hirik, Ekrem, Türkdil, Yıldız, Erdem ve Şahin'in çalışmalarında olduğu gibi anlamsal özelliklere de yer verilmiştir.

Bu çalışmanın konusu ise, Kutadgu Bilig adlı eserdeki duygu fiillerinin incelenmesidir. Kutadgu Bilig, 1069-1070 yılları arasında Yusuf Has Hacib tarafından yazılmıştır. 6645 beyitten oluşan ve mesnevi nazım şekline örnek teşkil eden bu eser, aynı zamanda bir siyasetname özelliği göstermektedir. Kutadgu Bilig'de Ay Toldı, Kün Togdı, Ögdilmiş ve Odgurmuş adı verilen dört sembolik şahıs (Devlet, Adalet, Akıl, Akıbet) birbirleriyle konuşturulur. Eser, bu yönüyle alegorik ve sembolik bir özelliğe sahiptir. Eserde insan hayatının toplum içerisindeki yeri, cemiyet ve devlet hayatının ideal bir şekilde düzenlenmesi için gereken bilgi ve faziletlerden bahsedilir (Ercilasun, 2011,s.293313).

Çalışmada, Savaş Şahin, Hüseyin Yıldız ve Erkan Hirik'in mental fiillerle ilgili çalışmalarından faydalanılarak söz konusu eserdeki duygu fiilleri ele alınmıştır.

Tespit edilen fiillerin etimolojisi incelenerek, DLT'de hangi anlamlarda kullanıldığ 1 parantez içerisinde gösterilmeye çalışılmıştır. Eserde tespit edilen fiillerin yer aldığı beyitler ve beyit anlamları da örneklendirilmeye çalışılmıştır.

Eserde tespit edilen fiiller ve fiillerin yer aldığı örnekler şöyledir:

\section{A. Duygu Fiilleri}

İnsan, düşünen bir varlıktır, denmektedir. İnsan, sadece düşünen değil, duyguları da olan bir varlıktır. Her türlü duygusunu, jest, mimikler ve davranışlar yanında sözcüklerle de ifade etmeye çalışır. İşte bireyin dış dünyayı anlamlandırmasında ve iç dünyasında biriktirdiği ve hissettiğini ifade etmesinde sözcükler içerisindeki en önemli öge fiillerdir. Kutadgu Bilig'de duyguları ifade etmek için kullanılan bazı fiiller ve örnekleri şöyledir:

\section{Dilek İfade Eden Fiiller}

\subsection{Kök Hâlindeki Fiiller}

kol - : istemek, dilemek.(< kol - “rica etmek, istemek.” DLT II, 25; kol - “istemek, rica etmek.” TTSKBS 2007: 535, -tur- OTWF 1991: 806, EDPT 1972: 616)

seningdin kolur ben basut küç bile

köni yol öze tut mini sen yüle

(KB. B. 3056/314)

(Sana yalvarırım, yardımın ve kudretin ile doğru yola yönelt, bana destek ol. ) 


\subsection{Gövde Hâlindeki Fiiller}

arzula - : arzulamak, istemek, dilemek.(< arzu (F.) “istek, heves" +la- Ergin 1993: 170)

arıglıknı barça kişiler tiler

arıg bolsa aş suv kişi arzular (KB. B. 2857/296)

(Temizliği bütün insanlar ister; yemek temiz olursa insan ona arzu duyar.)

esenleş - : esenlik dilemek, vedalaşmak. (esenle- "selamlamak." DLT I, 308/13)(< esen " sağ, salim, selamet"- le- Ergin 1993:170, -ş- Ergin 1993: 196, TTSKBS 2011: 341, EDPT 1972: 250)

kiming kırkta keçse tiriglik yılı esenleşti erke yigitlik tili (KB. B. 364/51)

(Kimin yaşı kırkı geçerse, gençlik insana veda eder.)

keçür - : geçirmek; bağışlamak.(< keçür- "evirip çevirmek, başarmak; bağışlamak.” DLT I, 47/15)(< keç- "geçmek, aşmak, ölmek; uykuya dalmak; bilincini yitirmek, sönmek. TTSKBS 2011: 359, -ür-, EDPT 1972: 698)

ay mungsuz dim sen bu munglug kulug

suyurkap keçürgil yazukın kamug (KB. C. 28/19)

(Ey bağışlayan Allah'ım, sen bu muhtaç kulun bütün günahlarını şefkatle bağışla.)

küse - : istemek, arzulamak, özlemek. (< küs- “küsmek.” DLT II 12/3, TTSKBS 2011: 592, küse- “ arzu etmek." TTSKBS 2011: 592, EDPT 1972: 749), küse - DLT (-).

küser men yigitlikke öknür özüm

ökünçüm asıg yok keser men sözüm (KB. B. 363/51)

(Sonra gençliğe özlem duyar ve pişman olursun ancak son pişmanlık fayda vermez, söz biter.)

ötün - : arz etmek, dilekte bulunmak, ricada bulunmak. （< öt - " bir şeye geçmek, delmek; boşalmak, -karın- sürmek" DLT I, 171/10; ötün- “büyüklerden bir dilek istemek.” DLT I, 376/12,EDPT 1972: 62).

negü tir eşitgil yazuklug kulı

köngül sırrı açtı kör ötnür tili （KB. B. 3770/379)

(Dinle, günahkâr kul ne der; bak, gönül sırrını açarak ne söyler.)

tile - : dilemek, istemek, beklemek, aramak. (< tile - DLT III 271/12, < *til + e- $/{ }^{*}$ t1 l +a-/t1l+êE- TTSKBS 2011: 284, EDPT 1972: 492)

neteg kim tiledi me boldı kamug

kimi kim tilese k1lur ol ulug (KB. B. 6/4)

(Nasıl ki diledi ve her şey oldu; böylece o kimi isterse, onu yüceltir.)

tilen - : dilemek, istemek, beklemek, aramak.(< tilen- "aranmak, dilenmek." DLT I 407/28, < til +e n- “dilenmek, dilencilik yapmak.” TTSKBS 2011: 284, EDPT 1972: 501)

usal bolma saklan kamug işte sen

bu saklık bile iki ajun tilen (KB. B. 443/58)

(Gafil olma, her işte tedbirli ol; her iki dünyayı bir tedbir ile iste.)

tilet - : istetmek, diletmek.(< tilet- “ istetmek, diletmek." DLT II 310/ 18, < til + e -t- TTSKBS 2011: 284, EDPT 1972: 494)

isiz bu yigitlik kanı kança bardı 
tilep bulmadım men neçe me tilettim (KB. B. 6524/644)

(Yazık bu gençliğe, hani, nereye gitti; ne kadar arasam da bulamadım.)

\subsection{Birleşik Fiiller}

\subsection{1. İsim + Yardımcı Fiille Oluşmuş Birleşik Fiiller}

du’acı bol - : duacı olmak. (< dua "Allah'a yalvarma, niyaz." Arapça bir kelimedir. OTAL

2016: 215)

kodu birgil emdi mini tengrike

du'açı bolayın sanga edgüke (KB. A. 3697/371)

(Beni şimdi Tanrı ibadetinde bırak, senin iyiliğin için duacı olayım.)

edgü kıl - : iyi etmek. (< edgü “iyi” DLT I, 34/11, ET. edgü > EAT *eygü / eyü > eyi > TT

iyi, TTSKBS 2011: 444, EDPT 1972: 53)

ukuşlug ked er öwke özdin yırat

biliglik beg er buşma edgü kıl at (KB. B. 322/47)

(Ey akıllı iyi yiğit, öfkeyi uzaklaştır; ey bilgili yiğit, hiddetlenme, iyi ad kazan.)

esenlik bul - : sağlik bulmak. (< esen “sağ, salim, selâmet.” DLT I, 62/5, TTSKBS 2011: 341, EDPT 1972: 248; esenlik “iyi sağlık, sağlamlık, güvenlik." EDPT 1972: 249)

esenlik bulup er yawa kilsa yaş

bu körksüz tiriglik bolur ay kadaş (KB. B. 4822/482)

(Hayat nimeti ile vaktini boşa geçiren insan kendisini ateşe atmış demektir; o hayvandan farksızdır.) inç esen bol - : huzur içinde olmak. (< inç "rahat, huzur içinde, müsterih. "DLT I, 74/18, TTSKBS () .

ilig altunı inç esen bolsunı

bayat birge barça tilek kolsunı (KB. C. 4957/945)

(Hükümdar sağ olsun ve huzur içinde yaşasın, Tanrı bütün dilek ve arzularını yerine getirsin.)

\subsubsection{Kurallı Birleşik Fiiller}

kolu tur - : isteyip durmak. (< kol- "istemek, dilemek." DLT II, 25/16, kol - "istemek, rica etmek." TTSKBS 2007: 535, OTWF 1991: 806)

küçi yetmişince katıglansu öz

yawa kılsa uzri kolı tursu öz (KB. C. 5286/526)

(İnsan gücü yettiği kadar gayret göstermeli, ihmâl ettikleri için de her vakit Allah'a tövbe etmelidir.)

\section{Mutluluk ve Birliktelik İfade Eden Fiiller}

\subsection{Gövde Hâlindeki Fiiller}

kawuş - : kavuşmak, yaklaşmak. (DLT II, 103/5, “ ayrı kalınan, sevilen bir kimseyle bir kimseyle bir araya gelmek, onu yeniden görmek." ET. (Uyg.) kavış- kaguş- , <* ka- b- + - ${ }^{\circ}$ ş- TTSKBS 2011: 48,EDPT 1972: 588)

ne körklüg sevinç ol kişi adrılıp

selamet kawuşsa tileyü kelip (KB. B 3295/ 334) 
(O kişi -akrabalarından- ayrılıp -sonra- isteyerek gelip kavuşsa ne büyük mutluluk!)

kawuştur - : kavuşturmak. (DLT II, 103/5, “ ayrı kalınan, sevilen bir kimseyle bir araya gelmek, onu yeniden görmek.” ET. (Uyg.) kavış- kaġuş- , <* ka- b- + - ${ }^{\circ}$ ş- TTSKBS 2011: 481, EDPT 1972: 588) okıdı kör ay toldıka kıldı yol bu ay toldı kirdi kawuşturdı kol

(KB. A. 766/93)

(Ay-Toldı'yı huzuruna çağırttı; Ay-Toldı geldi ve ellerini kavuşturdu.)

k1zart - : kizartmak, mutlu etmek. (< k1zart- “kizartmak.” DLT III, 431/17, “kizarmasına sebep olmak.” $<$ k1z- ar- t- TTSKBS 2011: 52,EPDT 1972: 685).

yag1 körse alp er kizartur mengiz

karışsa bodulur kızıl hem yagız (KB. B. 2384/252)

(Kahraman yiğidin, düşmanı görünce yüzü güler; düşmanla kapışınca, kızıl kana boyanır.)

kutad - : kutlu olmak, saadetli olmak, devletli olmak. (< kut " uğur, baht, talih; mutluluk.”, DLT I, 92/24; TTSKBS 2011: 58, EDPT 1972: 597)

bu kut kelse yalnguk kutadur köni

tümen arzu birle tatulap yir aş

(KB. A. 682/84)

(Mutluluk gelirse, insan gerçekten mutlu olur; bütün arzularına kavuşur, huzur içinde ölür.)

külçir - : gülmek. (< külsir- "gülümsemek, gülümser görünmek" DLT II 196-10), TTSKBS (-). M. Erdal, OTWF (1991: 538, EDPT 1972: 720)'da çIr- ekinin taklidi fiiller türettiğini ve birleşik ek yapısında olabileceğini belirtmiştir: külçir-< kül- çir- "gülümsemek". Ayrıca Eraslan (2012: 109), Ş. Tekin'in fonksiyonu kesin olarak bilinmeyen ekler arasında zikrettiği -çIr ekinin seyrek kullanılıp birkaç kelimede görüldüğünü ifade eder.

yüzi kızdı ongdı yana külçirip

sakındı bir ança uzun kiç irip (KB. B. 3845/387)

(Hem sevinç hem üzüntü yüzünde belirdi; sonra tekrar gülümsedi; bir müddet düşünceye daldı.)

tapış - : kavuşmak.(< tapış- "iki kişinin işlerinin birbirine tapşırması, vekilleşme, yekeleşme." (DLT I, 367/12)(< tap- "birbirini bulmak, kavuşmak." (1)ş- "buluşmak." EDPT 1972: 446)(< tap- "bulmak." + (1)ş- tır- "araştırmak." TTSKBS 2011: 859, tap- “ETÜ. tap- “hizmet etmek, kazanmak.", OTÜ. tap“tapmak, hizmet etmek; bulmak, sezmek.” TTSKBS 2011: 858).

tirig bolsa yalnguk tilep tapşur ok

esen bolsa barmış yana kawşur ok (KB. C. 3314/335)

(İnsanlar yaşarsa, arayarak birbirini bulurlar; ayrılan yine kesinlikle kavuşur.)

yiriş - : gülümsemek. (< yiriş- "yirişmek, yirilmek, ayrılmak; gülümsemek; kuvvetsizleşmek." DLT III, 73/1)(<yir- " yarmak, yırtmak, delmek." TTSKBS 2011: 1146-1147)(< yir-iş- "gülümsemek." EDPT 1972: 972)

yaşık koptı yirdin kötürdi başın

yaruk yüz küler teg yirişti tişin

(KB. A. 3953/398)

(Güneş yerden kalktı, başını kaldırdı; parlayan yüzün tebessümü gibi, parlak dişleri gözüktü.) 


\subsection{Birleşik Fiiller}

\subsection{1. İsim + Yardımcı Fiille Oluşmuş Birleşik Fiiller}

mengilik bol - : huzur bulmak. DLT (-)(< mengü “ebedî, daimî, sonsuz, sonsuzluk." TTSKBS 2011: 600, mengü “sonsuz, ebedî” EDPT 1972: 351)

mengilik bolur beg tükel kut başı

baġırsak kulı bolsa kılsa işi (KB. B. 1881/205)

(Kulu candan bağlı olur ve işini yaparsa, bey memnun olur ve tam bir saadete kavuşur.)

\section{Coşku ve Neşe İfade Eden Fiiller}

\subsection{Kök Hâlindeki Fiiller}

kom1 - : heyecanlanmak, coşmak, - bir şeye karş1- özlemek. (< kom1- "bir şeye karşı özlemek." (DLT III, 273/6),(< komı- “ bir işten sevinç, mutluluk duymak, memnun olmak." EDPT 1972: 629), TTSKBS $(-)$, TETTL (-).

takı arzuladı komıdı köngül

komısa köngül kör kişike mung ol (KB. C. 3854/388)

(Onu tekrar görmek istedi, gönlünü heyecanlandırdı; gönül coşarsa, insana dert olur.)

\subsection{Gövde Hâlindeki Fiiller}

beze - : süslemek, bezemek. (< beze- "bezemek, nakışlamak." DLT III, 263/26)(< bediz + e- " süslemek." TTSKBS 2011: 137, EDPT 1972: 310)

köngülüg bezedi yarukluk bile

tilimni bezedi tanukluk bile

(KB. B. 386/53)

(Gönlümü aydınlık ile süsledi; dilimi kelime-i şehadet ile bezedi.)

katgur - : gülerek katılmak. (< katgur- "gülerek katılmak." DLT II, 192/18)(< katgur- "gülerek katılmak." TTSKBS 2011: 475, < kat-ğur- EDPT 1972: 599)

kalık kaşı tügdi közi yaş saçar

çiçek yazdı yüz kör küler katgurar $\quad$ (KB. C. 80/25)

(Gök kaşını çattı, gözünden yaş serpiliyor; çiçek yüzünü açtı, bak, gülmekten katılıyor.)

komit - : heyecanlandırmak, coşturmak.(< komit- "coşturmak, heyecana getirmek." DLT II, 311/27)(< kom1- " bir işten sevinç, mutluluk duymak, memnun olmak." EDPT 1972: 629)

tilimlig kerek hem topulsa çerig

yitilik kerek ked komitsa erig

(KB. A. 2328/247)

(Ordular, dayanaklı olmalı, askeri coşturmak, harekete geçirmek için de kesin kararlı olmalıdır.)

\section{Sayg1 -Hürmet İfade Eden Fiil}

\subsection{Gövde Hâlindeki Fiil}

edle - : hürmet etmek, değer vermek, tesir etmek, ehemmiyet vermek, aklına getirmek.

(< ed-le- EDPT 1972: 57, DLT I, 286/8,)

elig urdı ilig mini edledi

bolu birdi evren özüm yokladı (KB. B. 1805/198)

(Hükümdar bana- çalışmalara- değer verdi, felek de özümü değerlendirdi, yükseldim.) 


\section{5. Öfke ve Nefret İfade Eden Fiil}

\subsection{Kök Hâlindeki Fiil}

k1z - : sinirlenmek, öfkelenmek. DLT (-) (< kız - “ateşlenmek, hararetlenmek." TTSKBS 2011: 522, TETTL 2016: 302,EDPT 1972: 685)

$$
\begin{aligned}
& \text { yüzi kızdı ongdı yana külçirip } \\
& \text { sakındı bir ança uzun kiç irip } \quad \text { (KB. B.3845/387) }
\end{aligned}
$$

(Hem sevinç hem üzüntü yüzünde belirdi; sonra tekrar gülümsedi; bir müddet düşünceye daldı.)

\section{SONUÇ}

Kutadgu Bilig'de toplam 28 duygu fiili tespit edilmiştir. Bu fiillerin tasnifi ve sayısal verileri şöyledir:

1) Dilek ve istek ifade eden 14 fiil tespit edilmiştir. Bu fiillerin tasnifi ve sayısal değeri şöyledir:

Kök hâlinde olan:1 (kol - fiili),

Gövde hâlinde olan: 8 ( arzula -, esenleş -, keçür -, küse -, ötün -, tile -, tilen -, tilet -.)

Birleşik fiiller: a) İsim + yard. eylemle oluşanlar: 4(duacı bol -, edgü kıl -, esenlik bol -, inç esen bol-

b) Kurallı birleşik fiiller: 1 (kolu tur - )

2) Mutluluk ve birliktelik ifade eden 8 fiil tespit edilmiştir. Bu fiiller şöyledir:

Gövde hâlinde: 7 (kawuş -, kawuştur -, kızart -, kutad -, külçir -, tapış -, yiriş -)

Birleşik fiiller: isim + yardımcı eylemle oluş. bir. f. 1 (mengilik bol - )

3) Coşku ve neşe ifade eden 4 fiil tespit edilmiştir. Bu fiillerin tasnifi ve sayısal verileri şöyledir:

Kök hâlinde olan: 1 (kom1 - ), Gövde Hâlinde olan: 3 (beze -, katgur -, komit -)

4) Sayg1 ve hürmet ifade eden gövde hâlinde bir (1) fiil tespit edilmiştir. (edle -)

5) Öfke ve nefret ifade eden kök hâlinde bir (1) fiil tespit edilmiştir. (kız -)

\begin{tabular}{ll}
\hline Dilek İfade Eden Fiiller & 14 \\
\hline Mutluluk ve Birliktelik İfade Eden Fiiller & 8 \\
\hline Coşku ve Neşe İfade Eden Fiiller & 4 \\
\hline Saygı ve Hürmet İfade Eden Fiiller & 1 \\
\hline Öfke ve Nefret İfade Eden Fiiller & 1 \\
\hline Toplam & 28 \\
\hline
\end{tabular}

Tablo 1. Kutadgu Bilig'de Duygu Fiilleri

Tabloda dilek, mutluluk, birliktelik ifade eden fiillerin, diğer duygu fiillerine göre daha çok kullanıldığı görülmektedir. Bu sonuç, Kutadgu Bilig'in adına uygun bir durumdur. "mengilik bolur beg tükel kut başı / baġırsak kulı bolsa kılsa işi”" (KB. B. 1881/205) (Kulu candan bağlı olur ve işini yaparsa, bey memnun olur ve tam bir saadete kavuşur.) "elig urdı ilig mini edledi bolu birdi evren özüm yokladı"(KB. B. 1805/198)(Hükümdar bana- çalışmalara- değer verdi, felek de özümü değerlendirdi, yükseldim.)beyitlerinden hareketle; eserin, insanın toplumda yaşamını sürdürebilmesinde toplum ve devlet ilişkisinin önemli olduğunu, hem birey hem de devlet için bilgi, fazilet ve çalışmanın önemini ve bu unsurların nasıl ve nerede kullanılacağını vurgulaması bakımından dikkate değerdir. "usal bolma saklan kamug işte sen / bu saklık bile iki ajun tilen （KB. B. 443/58)(Gafil olma, her işte tedbirli ol; her iki dünyayı bir tedbir ile iste.) "küçi yetmişince katıglansu öz/ yawa kılsa uzri kolı tursu öz"(KB. C. 5286/526)(İnsan gücü yettiği kadar gayret göstermeli, ihmâl ettikleri 
için de her vakit Allah'a tövbe etmelidir.) Her iş, hareket ve davranışı iki dünyayı da düşünerek tedbir ile yaparsak hem bu dünya hem de öbür dünyada mükâfatını görebileceğimize; bu kut kelse yalnguk kutadur köni / tümen arzu birle tatulap yir aş(KB. A. 682/84)(Mutluluk gelirse, insan gerçekten mutlu olur; bütün arzularına kavuşur, huzur içinde ölür.) insanların talihi, bahtı güzel olursa mutluluk ve huzura kavuşacağına dair hikmetli ifadeler ile Yusuf Has Hacib bir kez daha çağlar öncesinde yazılmış eserlerde insanlığa yol gösterici olmakta ve bu eserlerin muhtevasıyla bugün de yeniliğini ve değerini koruduğunu gözler önüne sermektedir.

\section{Kisaltmalar}

DLT Divânu Lûgati't-Türk

EDPT An Etimological Dictionary of Pre-Thirteenth Century Turkish

ETÜ. $\quad$ Eski Türkçe

F. $\quad$ Farsça

TETTL Tarihî ve Etimolojik Türkiye Türkçesi Lugati

TTSKBS Türkiye Türkçesinde Türkçe Sözcüklerin Köken Bilgisi Sözlüğü

OTAL Osmanlıca-Türkçe Ansiklopedik Lugat

OTWF Old Turkic Word Formation

OTÜ Orta Türkçe

\section{Kaynakça}

Abdiraim, Kıyal Kamchybekova. (2017). “Kırgız Türkçesinde Kara- Duyu Fiili Anlamsal Özellikleri ve Kavram Alanı Üzerine". Türk Dünyası, Dil ve Edebiyat Dergisil Turkish World, Journal of Language and Literature. Issue: 43 (Bahar- Spring 2017)- ISSSN:1301-0077.Ankara-Turkey. DOI Number: 10.24155/tdk.2017.0.

Arat, Reşit Rahmeti (1979). Kutadgu Bilig I-Metin. Ankara: TDK Yay.

Arat, Reşit Rahmeti (1994). Kutadgu Bilig II-Çeviri. Ankara: TDK Yay.

Atalay, Besim (1999). Divânü Lûgati't-Türk- Dizini. Cilt IV. Ankara: TDK Yay.

Ayan, Ekrem, Türkdil, Yakup. (2015). "Kazak Türkçesinde Dokunma Duyu Fiilleri ve Anlam Zenginliği", Turkish Studies, Vol. 10/4,s.95-114.

Bayraktar, Fatma Sibel.(2017). "Bulgar Sözlüğünde Yer Alan Türkçe Mental Fiiller Üzerine”, (XII. Uluslararası Büyük Türk Dili Kurultayı, 25-28 Eylül 2017, Bükreş, Romanya) Bildiri Kitabı, s. 458-466. (Kasim 2017).

Clauson, Sir Gerard (1972). An Etymological Dictionary of Pre-Thirteenth-Century Turkish. Oxford: Oxford University.

Develioğlu, Ferit (2016). Osmanlıca-Türkçe Ansiklopedik Lûgat. Ankara: Aydın Kitabevi Yay.

Eraslan, Kemal (2012). Eski Uygur Türkçesi Grameri. Ankara: TDK Yay.

Ercilasun, Ahmet Bican (2011). Başlangıçtan Yirminci Yüzyıla Türk Dili Tarihi. Ankara: Akçağ Yay.

Erdal, Marcel (1991). Old Turkinc Word Formation. Almanya: Wiesbaden. 
Erdem, Melek. (2007). “Oğuz Grubu Türk Lehçelerinde İletişim Fiilleri”, Modern Türklük Araştırmalar Dergisi, Cilt 4, Say1 2,s. 94-103.

Gülensoy, Tuncer (2011). Türkiye Türkçesinde Türkçe Sözcüklerin Köken Bilgisi Sözlüğü. Ankara: TDK Yay.

Hirik, Erkan; Çolak, Tuğba. (2017). “Türkçe Mental Fiillerde ‘Çok Katmanlılık”, IV. Uluslararası Türk Dünyası Araştırmaları Sempozyumu, C.1., s.261-268; 26-28 Nisan 2017, Niğde.

Hirik, Erkan (2018). Türkiye Türkçesinde Mental Fiiller. Ankara: Türk Kültürünü Araştırma Enstitüsü Yayınları-Dil Araştırmaları.

Özeren, Mehmet ve İrfan, Alan (2018). “Kırg1z Türkçesinde Mental Fiiller”. Atatürk Üniversitesi, Türkiyat Araştırmaları Enstitüsü Dergisi-61, ISSN-1300-9052, Ocak- 2018, 203-224.

Soydan Serpil, Özkan Aslı. (2019). “Kutadgu Bilig'deki Bazı Duygu Fiilleri Üzerine Bir Değerlendirme”. Niğde Ömer Halisdemir Üniversitesi, Sosyal Bilimler Enstitüsü Dergisi, Kapsosbil Sempozyum Özel Sayı. Cilt 1, Sayı: 2.27-32.

Şahin, Savaş (2012). Türkmen Türkçesinde Mental Fiiller. Doktora Tezi. Ankara: Gazi Üniversitesi.

Şahin, Savaş.(2012). “Mental Fiil Kavramı ve Türkmen Türkçesinde Mental Fiiller”. International Journal of Turkish Literature Culture Education, Teke Dergisi, Say1 1 / 4, s.45-62.

Yaylagül, Özen (2005). “Türk Runik Harfli Metinlerde Mental Fiiller”. Modern Türklük

Araştırmaları Dergisi. Cilt 2, Sayı: 1. 17-51.

Yaylagül, Özen. (2010). “Türkiye Türkçesindeki Duygu Fiilleri”, Modern Türklük Araştırmaları Dergisi, Cilt 7, Sayı:4, DOI:10. 1501/ MTAD.7.2010.4.63, Ankara Üniversitesi Dil ve Tarih-Cŏ̆rafya Fakültesi, Çağdaş Türk Lehçeleri ve Edebiyatları Bölümü, s.100-111.

Yıldız, Hüseyin (2016). Eski Uygurcada Mental Fiiller. Yayımlanmamış Doktora Tezi. Ankara: Gazi Üniversitesi. 


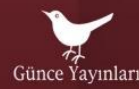

Prof. Dr. Önder Göçgün

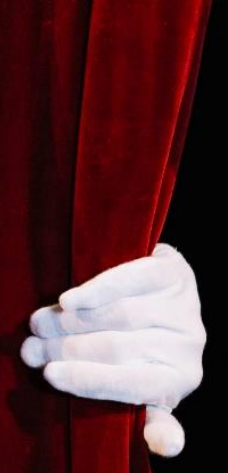

TIYYATRO DENEN HAYAT

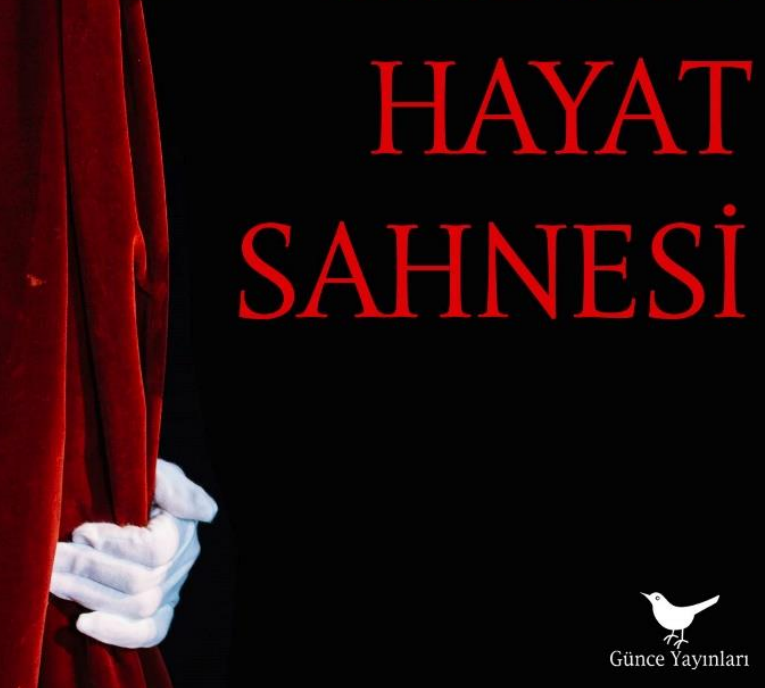

MUIIARREM DAYANC OKTAY YIVLI MACI'I BALIK MAIIMU'I BABACAN SLVIM SLERMEI
YASFMIN MUMCU BLDI் KOÇАKOĞLU NILÜLLLR ILLHAN MAKSUT YIĞITBAS SLL $\triangle M I I L \Lambda N$

\section{EDEBIYATINDA

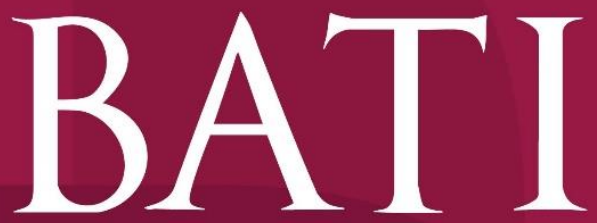 \\ EDEBIYATINDA
AKIMLAR \\ $\underset{\substack{\text { EDEBIYATINDA } \\ \text { AKIMLAR }}}{\mathrm{B} A T \mathrm{~T}}$}

editör

OKTAY YIVLI

HATICE FIRAT

YASEMIN MUMCU

OKTAY YIVLI

OĞUZHAN KARABURGU

BERNA AKYÜZ SIZGEN

NILÜFER ILHAN
ÜMMÜHAN TOPÇU

SEFA YÜCE

HANIFI ASLAN

METIN AKYÜZ

MEHMET SÜMER
YAKUP ÖZTÜRK
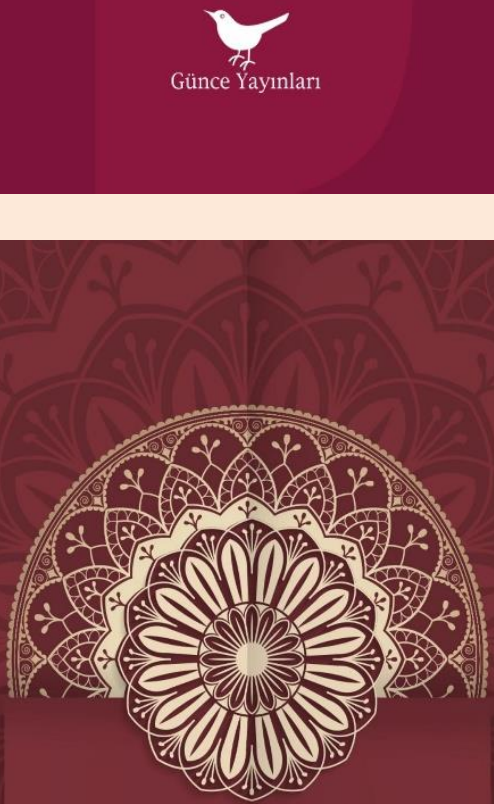

PROF. DR. ÖNDER GÖÇGÜN

$$
\begin{gathered}
\text { Türk } \\
\text { Tasavvuf } \\
\text { Siini }
\end{gathered}
$$

AÇIKLAMALI VE YORUMLU ÖRNEKLERLE 